\title{
Preparation, characterization, and in ovo vaccination of dextran-spermine nanoparticle DNA vaccine coexpressing the fusion and hemagglutinin genes against Newcastle disease
}

\author{
This article was published in the following Dove Press journal: \\ International Journal of Nanomedicine \\ 14 January 2016 \\ Number of times this article has been viewed
}

\author{
Masoumeh Firouzamandi ${ }^{1,2}$ \\ Hassan Moeini ${ }^{3}$ \\ Seyed Davood Hosseini ${ }^{4}$ \\ Mohd Hair Bejo' \\ Abdul Rahman Omar ${ }^{1,3}$ \\ Parvaneh Mehrbod ${ }^{3}$ \\ Mohamed E El Zowalaty ${ }^{5}$ \\ Thomas J Webster ${ }^{6}$ \\ Aini Ideris ${ }^{1,3}$ \\ 'Department of Veterinary Clinical \\ Studies, Faculty of Veterinary \\ Medicine, Universiti Putra Malaysia, \\ Selangor, Malaysia; ${ }^{2}$ Department of \\ Pathobiology, Faculty of Veterinary \\ Medicine, University of Tabriz, \\ Iran; ${ }^{3}$ Laboratory of Vaccine and \\ Immunotherapeutics, Institute of \\ Bioscience, Universiti Putra Malaysia, \\ Selangor, Malaysia; ${ }^{4}$ Razi Vaccine \\ and Serum Research Institute, Arak, \\ Iran; ${ }^{5}$ Biomedical Research Center, \\ Vice President Office for Research, \\ Qatar University, Doha, Qatar; \\ ${ }^{6}$ Department of Chemical Engineering, \\ Northeastern University, Boston, \\ MA, USA
}

\begin{abstract}
Plasmid DNA (pDNA)-based vaccines have emerged as effective subunit vaccines against viral and bacterial pathogens. In this study, a DNA vaccine, namely plasmid internal ribosome entry site-HN/F, was applied in ovo against Newcastle disease (ND). Vaccination was carried out using the DNA vaccine alone or as a mixture of the pDNA and dextran-spermine (D-SPM), a nanoparticle used for pDNA delivery. The results showed that in ovo vaccination with $40 \mu \mathrm{g}$ pDNA/egg alone induced high levels of antibody titer $(P<0.05)$ in specific pathogenfree (SPF) chickens at 3 and 4 weeks postvaccination compared to 2 weeks postvaccination. Hemagglutination inhibition (HI) titer was not significantly different between groups injected with $40 \mu \mathrm{g}$ pDNA $+64 \mu \mathrm{g}$ D-SPM and $40 \mu \mathrm{g}$ pDNA at 4 weeks postvaccination $(P>0.05)$. Higher antibody titer was observed in the group immunized with $40 \mu \mathrm{g}$ pDNA/egg at 4 weeks postvaccination. The findings also showed that vaccination with $40 \mu \mathrm{g} \mathrm{pDNA} / \mathrm{egg}$ alone was able to confer protection against Newcastle disease virus strain NDIBS002 in two out of seven SPF chickens. Although the chickens produced antibody titers 3 weeks after in ovo vaccination, it was not sufficient to provide complete protection to the chickens from lethal viral challenge. In addition, vaccination with pDNA/D-SPM complex did not induce high antibody titer when compared with naked pDNA. Therefore, it was concluded that DNA vaccination with plasmid internal ribosome entry site-HN/F can be suitable for in ovo application against ND, whereas D-SPM is not recommended for in ovo gene delivery.
\end{abstract}

Keywords: Newcastle disease, DNA vaccine, in ovo vaccination, Newcastle disease virus, dextran-spermine nanoparticle, hemagglutinin and fusion

\section{Introduction}

The administration of DNA vaccines is an advanced approach to achieve specific immune system activation. ${ }^{1,2}$ The advantages of DNA vaccines such as the capacity to be delivered in ovo, the potential to overcome maternal immunity, non-requirement for cold chain transport, and the ability to mix with immunological factors to reach high efficiency have made them more attractive for use in the poultry industry. It has been demonstrated that recombinant DNA transfection into avian embryos is a problematic approach. ${ }^{2}$ Hence, in adult animals, DNA vaccines are most commonly delivered via intradermal or intramuscular injections; a few studies have focused on embryonic administration. ${ }^{3-5}$ Administration of plasmid DNA ( $\mathrm{pDNA}$ ) containing the reporter beta galactosidase gene into the avian embryo body produced the protein, although it can increase the mortality rate. ${ }^{3}$ Avian embryo is competent immunologically after the 17 th day of embryonic stages. ${ }^{6-8}$
Correspondence: Aini Ideris Department of Veterinary Clinical Studies, Faculty of Veterinary Medicine, Universiti Putra Malaysia, 43400 UPM Serdang, Selangor, Malaysia

Tel +60 389466021

Email aiini@upm.my
International Journal of Nanomedicine 2016: I 259-267 (c) (i) () 2016 Firouzamandi et al. This work is published and licensed by Dove Medical Press Limited. The full terms of this license are available at https://www.dovepress.com/terms.php a for commercial use of this work, please see paragraphs 4.2 and 5 of our Terms (https://www.dovepress.com/terms.php). 
Therefore, it was hypothesized that a DNA vaccine could be administered into the amniotic sac of avian embryos to induce immunity at this stage.

Few factors such as cell membrane, in vivo stability, endosome escape, nuclear entry, and cytosolic transport act as barriers that inhibit the delivery of DNA into the host cells. DNA vaccines can be efficiently delivered using cationic lipids and/or cationic polymers. A study showed that DNA when covered by these particles resulted in a complex with positive charge that enhanced the endocytosis process through which the DNA entered the cell. Cationic polymers created more stable complexes than cationic lipids; thus, they provide more protection to the vaccines through cellular trafficking. ${ }^{7-10}$ Cationic polysaccharides are biodegradable and nontoxic and can be easily modified to exhibit different physicochemical properties. ${ }^{11}$ Usage of biodegradable polysaccharide carriers are especially appropriate for biological applications such as transaction, because they are soluble in water and freely transported to the cells. ${ }^{12}$ Polysaccharide dextran is a complex, diverged glucan with a chain length from 3 to $2,000 \mathrm{kDa}$ and is prepared by using many glucose molecules. Recently, dextran-spermine (D-SPM) has been developed as a novel cationic polymer for gene delivery. A recent study has suggested a new biodegradable polycation made up of natural components, which is efficient in transfecting tissues and cells in vitro and in vivo. ${ }^{13}$ This polycation has shown an effective transfection for a range of cell lines and genes in serum-poor or serum-free medium. ${ }^{14} \mathrm{D}$-SPM polycations have been found to be active in transfecting a wide range of cell lines in vitro. ${ }^{15}$ Therefore, the objectives of the present study were: 1) to determine that a DNA plasmid coexpressing the fusion $(\mathrm{F})$ and hemagglutinin $(\mathrm{HN})$ proteins of Newcastle disease virus (NDV) can be a potential vehicle for successful vaccination in ovo against ND; and 2) to test whether the cationic polysaccharide D-SPM can be used to enhance the efficacy of in ovo delivery of the DNA vaccine against ND.

\section{Materials and methods Construction of DNA vaccine}

The plasmid internal ribosome entry site (pIRES) coexpression vector containing multiple cloning sites (MCS) such as MCS A and MCS B with a size of $6.1 \mathrm{~kb}$ (Clontech, Palo Alto, CA, USA) was used to construct a DNA plasmid encoding the $F$ and $H N$ genes of NDV AF2240 strain. The full lengths of the $F$ and $H N$ genes were amplified using reverse transcription polymerase chain reaction (RT-PCR) using a pair of F-specific primers and $\mathrm{HN}$-specific primers with sequence for the restriction enzymes NheI and MluI, and SalI and NotI, respectively, introduced into the forward and reversed primers regard to conserving frameshift of sequences:

F-For: 5'AATTCGGCTAGCACCATGGGCTCCAAG TCTT3'

F-Rev: 5'GGCACGCGTCTAGCTGCCAGAATTGA CGCGCA3'

HN-For: 5'CAGTCGACGTCATGGGGAACCAGGC CTCACAA3'

HN-Rev: 5'GAGCGGCCGCCCTATTGACAAGAAT TCAGGCCAT3'.

The RT-PCR products of $F$ and $H N$ genes with a length of 1,722 and 1,950 base pairs (bp), respectively, were amplified and cloned into the NheI and MluI (inserted into MCS A) and SalI and NotI (inserted into MCS B) of the pIRES vector to the construct pIRES-HN/F DNA plasmid. The construct was purified using an endotoxin-free plasmid purification kit (Qiagen $\mathrm{NV}$, Venlo, the Netherlands) following verification of the orientation and nucleotide sequence of the inserts by double-stranded sequencing. Expression of both $\mathrm{HN}$ and $\mathrm{F}$ genes together in a $\mathrm{pIRES}-\mathrm{HN} / \mathrm{F}$ plasmid was confirmed using both indirect immunofluorescence and Western blotting techniques.

\section{Preparation of pDNA/D-SPM complex}

D-SPM was prepared as previously described by Abedini et al. ${ }^{16} \mathrm{pDNA} / \mathrm{D}-\mathrm{SPM}$ nanoparticles were prepared by mixing pDNA and D-SPM at various concentrations in aqueous solution. A volume of $100 \mu \mathrm{L}$ of DNase-free water was taken in five separate tubes containing $8,12,16,18$, and $20 \mu \mathrm{g}$ of D-SPM and placed in a sonicator (Branson, Danbury, CT, USA) for 30 minutes. To each test tube, $10 \mu \mathrm{g}$ of pDNA was added and the solutions were pipetted up and down three to five times and then placed in an orbital mixer for 10 minutes at room temperature. The solutions of pDNA and D-SPM were mixed and gently agitated for 30 minutes to form selfassembled pDNA/D-SPM complexes.

\section{Characterization of the self-assembled pDNA}

The reliability of covering pDNA by D-SPM was tested on $1 \%$ agarose gel. The formation of DNA complexes was also confirmed by transmission electron microscopy (TEM). Fifty microliters of the sample was kept on a copper grid for 5 minutes; excess solution was blotted off using filter paper and air-dried for 5 minutes before viewing by TEM.

\section{Particle size assayed by NANOPHOX}

Fresh pDNA/D-SPM complex was prepared with a fixed concentration of pDNA and a varying concentration of 
D-SPM and then the mean particle size was analyzed by a particle size analyzer (NANOPHOX, Sympatec, Germany). The size of all the dispersed samples in nuclease-free water was determined at $25^{\circ} \mathrm{C}$ in triplicate. Photon cross correlation sensor present in this analyzer allowed for the simultaneous determination of particle size and stability in a range, approximately, of $1 \mathrm{~nm}$ to several micrometers in opaque suspensions and emulsions. ${ }^{17}$

\section{Zeta potential and size measurement}

Zeta potential is commonly used to characterize the surface charge property of nanoparticles. ${ }^{18}$ Size and zeta potential of nanoparticles were determined using a laser particle size analyzer (Malvern, Zeta, Worcestershire, UK). A tenfold dilution of the sample in pure water in a total volume of $1 \mathrm{~mL}$ was subjected to a particle size analyzer at $25^{\circ} \mathrm{C}$. The measurement was based on the electrophoretic mobility $(\mu \mathrm{m} / \mathrm{s})$ of the particles which was converted to zeta potential by inbuilt software based on the Helmholtz-Smoluchowski equation.

\section{In ovo vaccination of SPF embryo}

Eighteen-day-old embryonated specific pathogen-free (SPF) eggs were randomly divided into four groups (15 eggs per group). The eggs were inoculated with $40 \mu \mathrm{g}$ pIRES-HN/F, $20 \mu \mathrm{g}$ pIRES-HN/F +32 $\mu \mathrm{g}$ D-SPM, and $40 \mu \mathrm{g}$ pIRES$\mathrm{HN} / \mathrm{F}+\mathrm{D}-\mathrm{SPM}$ complex or the empty plasmid. The egg shells were disinfected and the vaccines were injected via the aminio-allantoic cavity through a small hole made at the air sacs with 21-gauge needle followed by sealing the holes and continued the incubation of the eggs. After hatching, the chicks had free access to feed and water. Bleeding was carried out at 2, 3, and 4 weeks post-immunization; total serum antibody titers were measured by an indirect enzyme-linked immunosorbent assay (ELISA) Kit (IDEXX, Westbrook, ME, USA) and hemagglutination inhibition (HI) test as previously described. ${ }^{19}$ The chickens were treated and handled according to the protocols approved by the Institutional Animal Care and Use Committee (IACUC) of the Faculty of Veterinary Medicine (AUP no. 12R1541), Universiti Putra Malaysia.

\section{Virus challenge}

After 4 weeks of in ovo vaccination, the vaccinated chickens in all groups were challenged with intranasal administration of $10^{5}$ mean egg infection dose $\left(\mathrm{EID}_{50}\right)$ of either NDV strain AF2240 or NDV strain IBS002 in a volume of $0.1 \mathrm{~mL}$ viral suspensions per chick. The chickens were monitored daily after challenge for 10 days and the numbers of dead chickens were recorded.

\section{Statistical analysis}

Data were analyzed by Student's $t$-test and statistical significance was set at $P<0.05$. The results were expressed as mean \pm standard error of the mean. All the analyses were carried out using Minitab 15 Statistical Software (Minitab Inc., University Park, PA, USA) and Microsoft Excel 2010 (Microsoft Corporation, Redmond, WA, USA).

\section{Results}

\section{Agarose gel electrophoresis of pDNA/ $D-S P M$ complex at different ratios}

The DNA vaccine pIRES-HN/F was constructed to express $\mathrm{HN}$ and $\mathrm{F}$ genes of NDV strain AF2240. The pDNA/D-SPM nanoparticles were prepared by mixing pIRES-HN/F and D-SPM at various concentrations. The formation of nanoparticles was tested by performing electrophoresis of the samples on $1 \%$ agarose gel, where the absence of DNA band on the gel indicates the initial formation of a stable complex (Figure 1).

\section{Particle size analysis}

The formation of nanoparticles and particle sizes of the pDNA/D-SPM complexes were also checked by TEM. Good agglomeration and a particle size of $\sim 70-130 \mathrm{~nm}$ were obtained when a mixture of $10 \mu \mathrm{g}$ of pDNA and $16 \mu \mathrm{g}$ of D-SPM was used to prepare the nanoparticles (Figure 2). In addition, the particle size of the $\mathrm{pDNA} /$ dextran complexes was determined by nanophox equipment (NANOPHOX). As shown in Figure 3, a particle size of 10-100 nm was obtained when a mixture of $10 \mu \mathrm{g}$ of pDNA and $16 \mu \mathrm{g}$ of D-SPM was used.

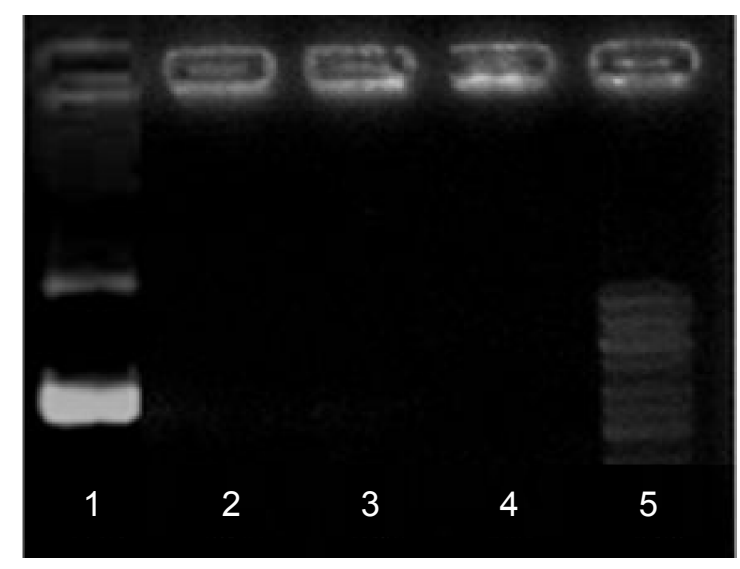

Figure I Agarose gel electrophoresis of the pDNA/D-SPM complex at different ratios.

Notes: Line I, free pDNA plasmid; lines 2-4, pDNA/D-SPM complexes at ratios 12, 16 , and $18 \mu \mathrm{g}$, respectively; line 5, GeneRuler GeneRuler ${ }^{\mathrm{TM}}$ DNA ladder I kb (Fermentas Canada, Burlington, ON, Canada).

Abbreviations: pDNA, plasmid DNA; D-SPM, dextran-spermine. 


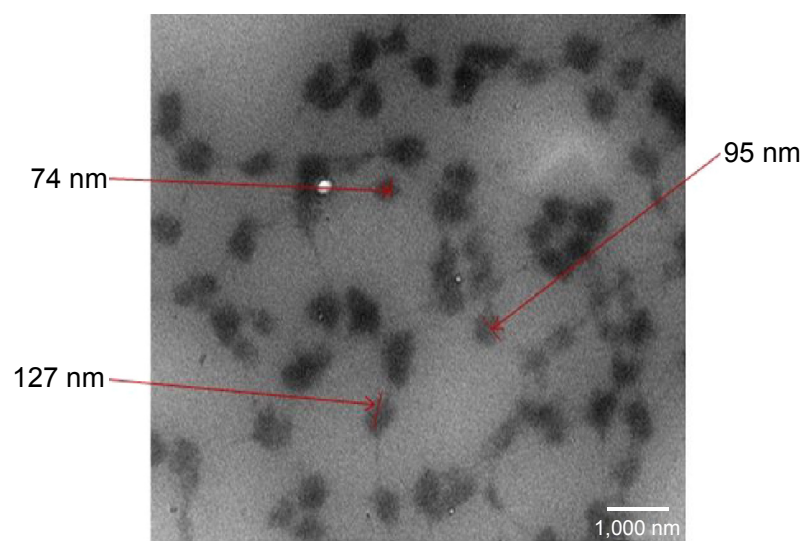

Figure 2 Particle size analysis of pDNA/D-SPM complexes by transmission electron microscopy (TEM).

Notes: Nanoparticle sizes between 74 and $127 \mathrm{~nm}$ were obtained from the pDNA/ dextran complexes. Scale bar $=1,000 \mathrm{~nm}$. These arrows point to the size of pDNA/ D-SPM complexes.

Abbreviations: pDNA, plasmid DNA; D-SPM, dextran-spermine.

\section{Size distribution of pDNA with D-SPM nanoparticle complexes}

In addition, the size distribution of the pDNA/D-SPM complexes were determined with a Zetasizer 3000 HSA (Malvern); when a mixture of $10 \mu \mathrm{g}$ of pDNA and $16 \mu \mathrm{g}$ of D-SPM nanoparticles was used, DNA nanoparticles of $75 \mathrm{~nm}$ size were obtained, as shown in Figure 4A.

\section{Zeta potential report of pDNA with D-SPM nanoparticle complexes}

A zeta potential in the range of $25-30 \mathrm{mV}$ was used for the preparation of pDNA/D-SPM complexes in a ratio of $10 \mu \mathrm{g}$ pDNA to $16 \mu \mathrm{g}$ of D-SPM (Figure 4B).
As expected, the zeta potential of pDNA alone was found to be in a range of -55 to $-60 \mathrm{mV}$ (Figure $5 \mathrm{~A}$ ). The backbone of DNA is highly charged and each bp carries two unit negative charges and each phosphate group carries one unit negative charge. The surface charge of nanoparticles with a zeta potential around $\pm 30 \mathrm{mV}$ has been revealed to be stable in suspension, and this surface charge stops aggregation of the particles. For D-SPM alone, the surface charge was determined to be in a range of $30-35 \mathrm{mV}$ (Figure 5B).

\section{In ovo immunization of SPF chickens}

In ovo immunization was carried out using naked DNA plasmid and pDNA + D-SPM complexes. After hatching, an immune response was assessed at 2, 3, and 4 weeks postvaccination.

\section{NDV antibody response by ELISA}

The antibody titer was evaluated at a serum dilution of 1:500 using commercial ELISA kit (IDEXX). The positive control mean was 0.165 and the negative control mean was 0.046 .

ELISA results were presented as an S/P ratio. An S/P ratio is determined by dividing the absorbance units (ELISA score) of the sample in question by the ELISA score of a positive control analyzed alongside the test sample(s). An S/P ratio is directly correlated with the amount of target antigen present in the sample.

As shown in Table 1 and Figure 6, no anti-NDV immune response was detected in the controls vaccinated with the empty plasmid. Antibody levels remained low 2 weeks after

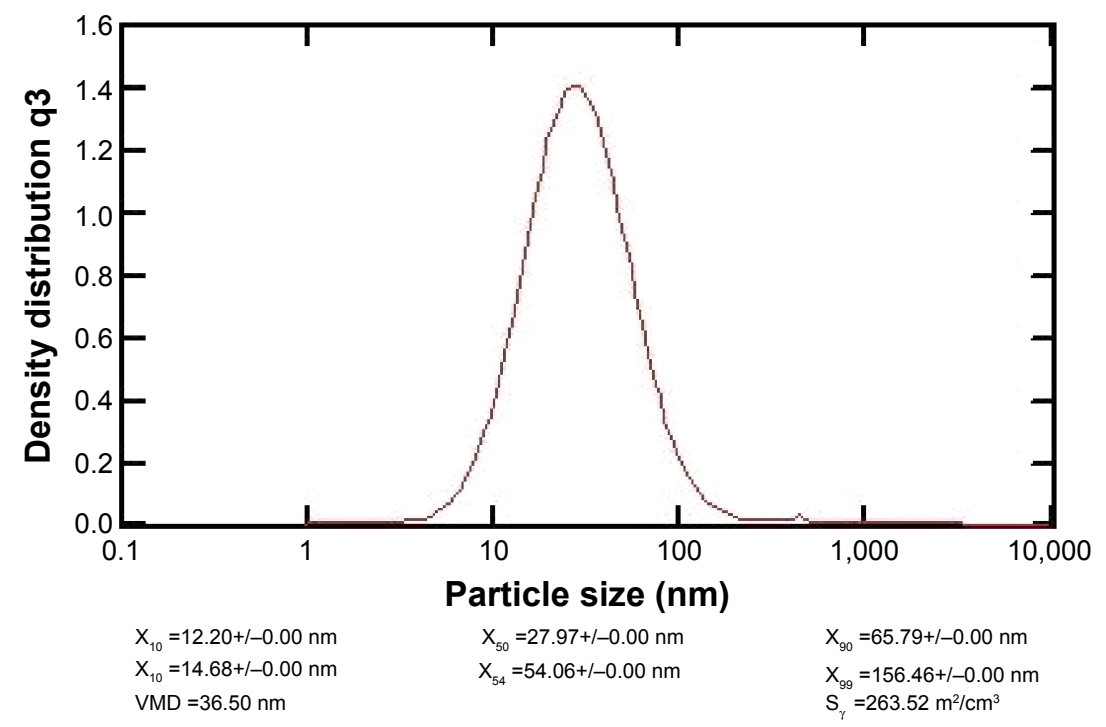

Figure 3 NANOPHOX particle size analysis of the pDNA/D-SPM complexes.

Abbreviations: pDNA, plasmid DNA; D-SPM, dextran-spermine; VMD, volume mean diameter. 
A

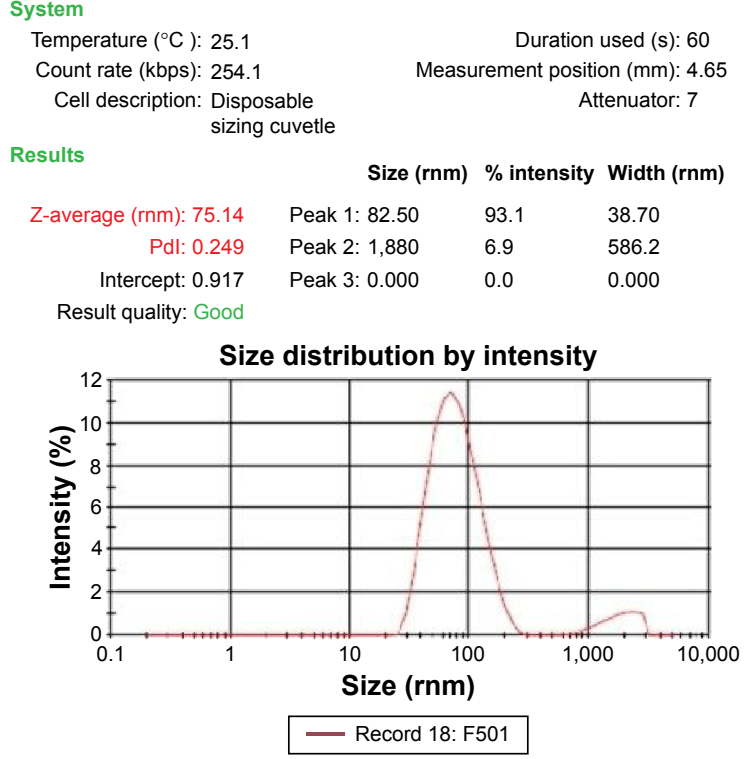

B System

Temperature $\left({ }^{\circ} \mathrm{C}\right): 25.1$

Count rate (kbps): 274.5

Cell description: Clear disposable zeta cell

Results

$\begin{array}{clll} & \text { Mean }(\mathbf{m V}) & \text { Area }(\%) & \text { Width }(\mathbf{m V}) \\ \text { Zeta potential }(\mathrm{mV}): 26.3 & \text { Peak 1: } 23.3 & 100.0 & 5.94 \\ \text { Zeta deviation }(\mathrm{mV}): 5.94 & \text { Peak 2: } 0.00 & 0.0 & 0.00 \\ \text { Conductivity }(\mathrm{mS} / \mathrm{cm}): 0.0790 & \text { Peak 3: } 0.00 & 0.0 & 0.00\end{array}$

Result quality: Good

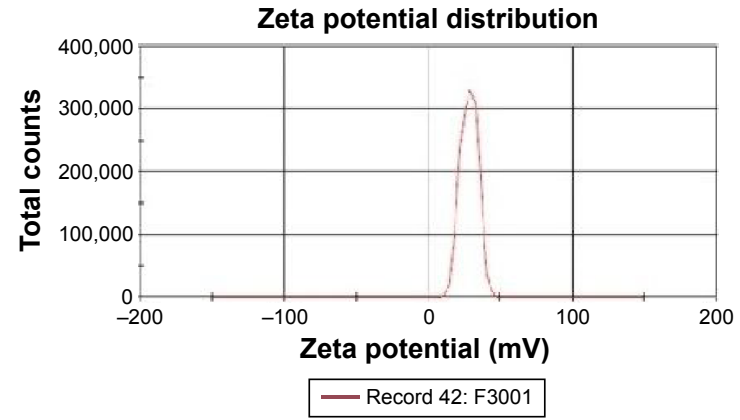

Figure 4 Zeta potential of pDNA and D-SPM.

Notes: (A) Size distribution of pDNA with D-SPM nanoparticle complexes by Zetasizer 3000 HSA. Plasmid DNA and D-SPM nanoparticles when used in a ratio of I0:16 produced a complex of size $75 \mathrm{~nm}$. (B) Zeta potential report of pDNA/D-SPM complexes. The range of zeta potential of the pDNA/D-SPM complexes at a ratio of I0 of $\mu \mathrm{g}$ plasmid DNA to $14 \mu \mathrm{g}$ or $16 \mu \mathrm{g}$ of D-SPM was $25-30 \mathrm{mV}$.

Abbreviations: pDNA, plasmid DNA; D-SPM, dextran-spermine.

in ovo immunization in all the vaccinated groups. A higher antibody titer was observed in the group immunized with $40 \mu \mathrm{g}$ pDNA at 4 weeks postvaccination; however, it was not significant compared to the chickens immunized with
$40 \mu \mathrm{g}$ pDNA $+64 \mu \mathrm{g}$ dextran complex $(P>0.05)$. The lowest antibody titer was obtained in groups vaccinated with $20 \mu \mathrm{g}$ pDNA $+32 \mu \mathrm{g}$ dextran complex compared to other vaccinated groups $(P<0.05)$.
A System

Temperature $\left({ }^{\circ} \mathrm{C}\right): 24.9$

Count rate (kbps): 23.9

Cell description: Clear disposable zeta cell

Results

Zeta potential $(\mathrm{mV}):-57.1$ Zeta deviation (mV): 5.87 Conductivity (mS/cm): 0.0067 Result quality: Good

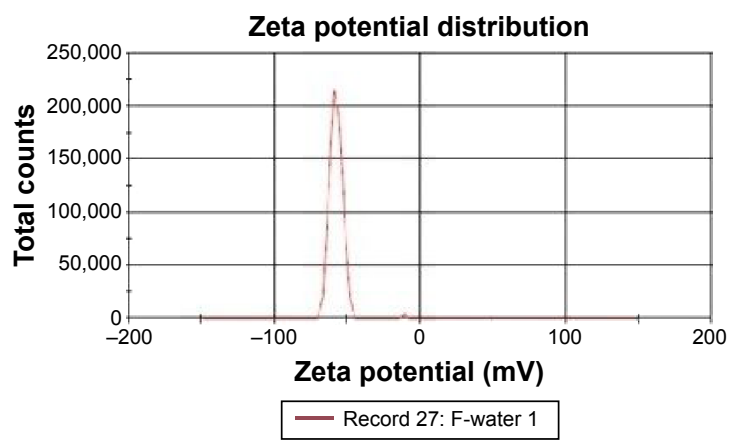

B
Measurement position (mm): 2.00 Attenuator: 11

Mean $(\mathrm{mV}) \quad$ Area $(\%) \quad$ Width $(\mathrm{mV})$

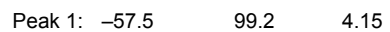

$\begin{array}{llll}\text { Peak 2: } & -10.5 & 0.8 & 1.19 \mathrm{e}-7\end{array}$

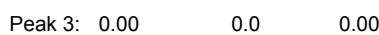

00
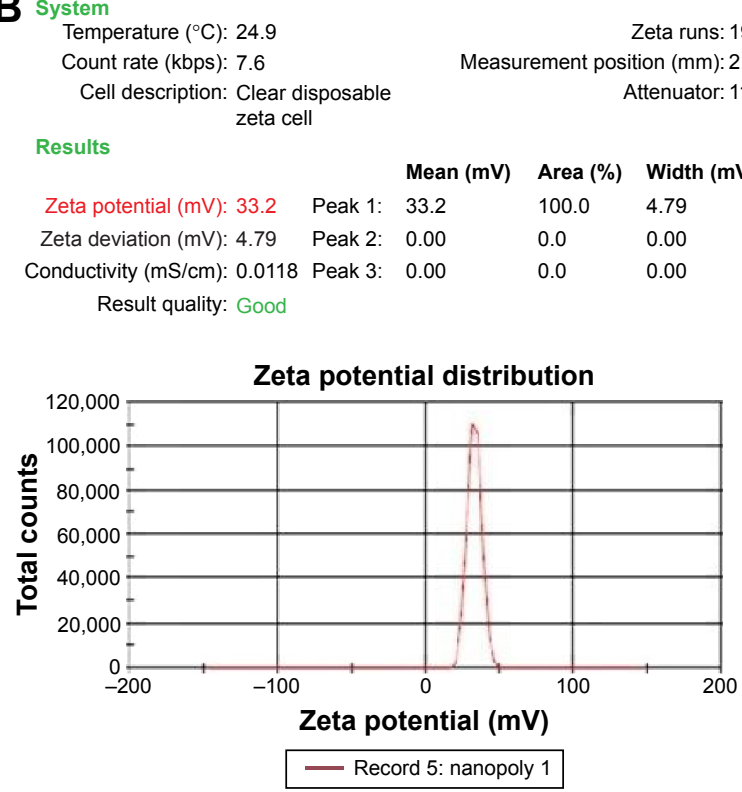

Figure 5 Zeta potential of pDNA and D-SPM.

Notes: (A) Zeta potential report of pDNA alone. The zeta potential of backbone plasmid DNA ranged from -55 to $-60 \mathrm{mV}$. (B) Zeta potential report of D-SPM alone. The surface charge of D-SPM alone was determined to be in a range of $30-35 \mathrm{mV}$. Abbreviations: pDNA, plasmid DNA; D-SPM, dextran-spermine. 
Table I Analysis of S/P ratios of ELISA results

\begin{tabular}{|c|c|c|c|}
\hline \multirow[t]{2}{*}{$\overline{\text { Group }}$} & \multicolumn{3}{|c|}{ S/P ratio of ELISA results } \\
\hline & 2 weeks & 3 weeks & 4 weeks \\
\hline pIRES-HN/F (40 $\mu \mathrm{g}$ pDNA) & $0.038 \pm 0.00$ & $0.248 \pm 0.02$ & $0.272 \pm 0.02$ \\
\hline pIRES-HN/F (40 $\mu g$ pDNA + D-SPM) & $0.035 \pm 0.00$ & $0.209 \pm 0.01$ & $0.25 \mathrm{I} \pm 0.02$ \\
\hline pIRES-HN/F (20 $\mu \mathrm{g}$ pDNA + D-SPM) & $0.022 \pm 0.04$ & $0.063 \pm 0.00$ & $0.085 \pm 0.02$ \\
\hline PIRES & 0.00 & 0.00 & 0.00 \\
\hline
\end{tabular}

Note: S/P ratio = Sample mean (mean of optical absorbance) - negative control mean/positive control mean - negative control mean.

Abbreviations: ELISA, enzyme-linked immunosorbent assay; pIRES, plasmid internal ribosome entry site; HN, hemagglutinin; F, fusion; pDNA, plasmid DNA; D-SPM, dextran-spermine.

\section{NDV-HN antibody titers by $\mathrm{HI}$ test}

The HI test was carried out on serum samples with four hemagglutination (HA) units of the mucosal LaSota vaccine. A twofold dilution of each serum was made and titers were expressed as $\log 2$ values of the highest dilution of serum inhibiting hemagglutination. The mean $\mathrm{HI}$ titers are shown in Table 2. HI titer was not significantly different between the groups injected with $40 \mu \mathrm{g}$ pDNA $+64 \mu \mathrm{g}$ D-SPM $(3.5 \pm 0.51)$ and $40 \mu \mathrm{g}$ pDNA (3.43 \pm 0.22 ). However, the mean HI titer was significantly lower in the groups vaccinated with $20 \mu \mathrm{g}$ pDNA $+32 \mu \mathrm{g}$ D-SPM $(2.73 \pm 0.04)$ compared to the other vaccinated groups.

\section{Virus challenge}

Four weeks post-immunization, chickens were challenged with NDV AF2240 and IBS002 strains. In the AF2240-challenged chickens, regular death was first detected 3 days post-challenge and the last death was recorded on the fifth day for all the control chickens. Clinical signs such as the wing or leg paralysis and weakness were observed on the third day postchallenge and the chickens began to die. After 1 week postchallenge, all the chickens in all the vaccinated groups died (Table 3). However, chickens immunized with pIRES-HN/F ( $40 \mu \mathrm{g} \mathrm{pDNA} / \mathrm{egg}$ ) and challenged with IBS002 were more active and showed no signs of disease even after 3 days postchallenge and finally two chickens survived. Furthermore, one chicken in each pIRES-HN/F group vaccinated with $40 \mu \mathrm{g}$ pDNA + D-SPM/egg or $20 \mu \mathrm{g}$ pDNA + D-SPM/egg died 8 days post-challenge (Table 4 ).

In all the challenged chickens, depression and loss of appetite were observed. Severe manifestations such as edema, hemorrhages, and necrosis of respiratory tissue were found in dead chickens of the control group, whereas no significant gross lesions were found in the vaccinated group.

However, pIRES-HN/F-immunized chickens showed no signs of the disease even after 3 days of the challenge and finally two chickens survived (Table 4).

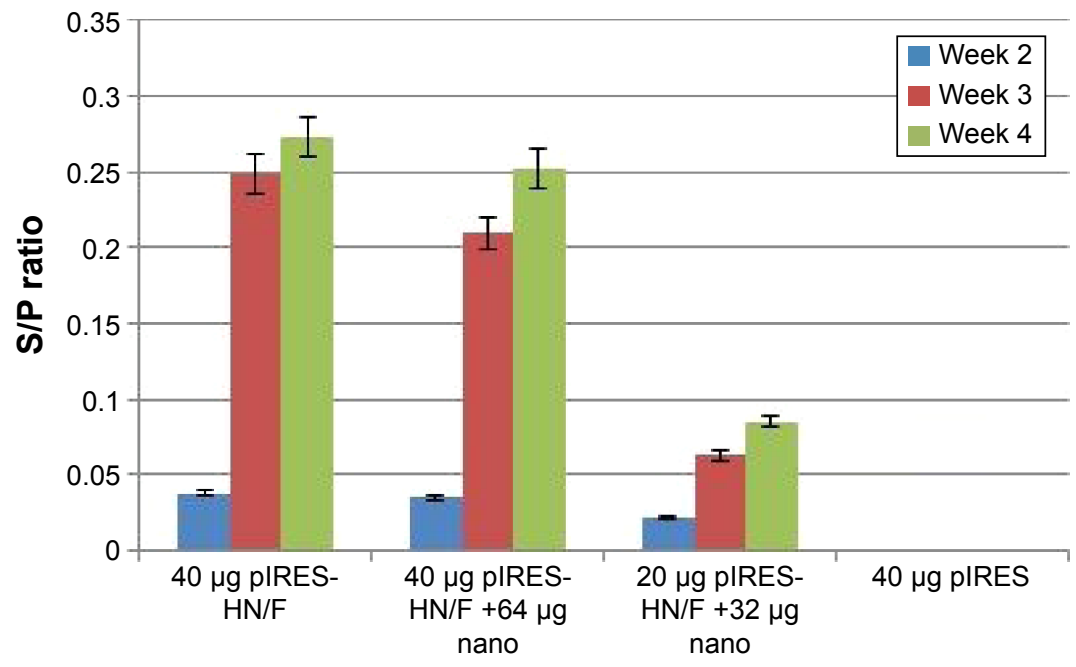

Figure 6 Mean S/P ratio of ELISA result after in ovo immunization with pIRES-HN/F or pIRES-HN/F-D-SPM complexes.

Notes: The error bars show standard deviation of means. S/P ratio = Sample mean (mean of optical absorbance) - negative control mean/positive control mean - negative control mean.

Abbreviations: ELISA, enzyme-linked immunosorbent assay; pIRES, plasmid internal ribosome entry site; HN, hemagglutinin; F, fusion; D-SPM, dextran-spermine; Nano, nanoparticle. 
Table 2 Mean antibody titers determined by $\mathrm{HI}$ test $\left(\log _{2}\right)$ of SPF embryonated eggs after immunization with different vaccination programs (geometric mean \pm SD)

\begin{tabular}{llll}
\hline Group & \multicolumn{4}{l}{ Mean $\mathrm{HI}$ titer in different weeks of postvaccination $\left(\log _{2}\right)$} \\
\cline { 2 - 4 } & $\mathbf{2}$ weeks & $\mathbf{3}$ weeks & $\mathbf{4}$ weeks \\
\hline PIRES-HN/F $(40 \mu \mathrm{g}$ PDNA) & $1.93 \pm 0.47$ & $2.14 \pm 0.53$ & $3.43 \pm 0.22$ \\
PIRES-HN/F $(40 \mu \mathrm{g}$ PDNA + D-SPM) & $1.36 \pm 0.49$ & $1.7 I \pm 0.61$ & $3.5 \pm 0.5 \mathrm{I}$ \\
PIRES-HN/F $(20 \mu \mathrm{g}$ PDNA + D-SPM) & $1.64 \pm 0.50$ & $1.64 \pm 0.5$ & $2.73 \pm 0.04$ \\
PIRES & $1.1 \pm 0.31$ & $1.1 \pm 0.31$ & $1.1 \pm 0.31$ \\
\hline
\end{tabular}

Abbreviations: $\mathrm{HI}$, hemagglutination inhibition; SPF, specific pathogen-free; pIRES, plasmid internal ribosome entry site; HN, hemagglutinin; F, fusion; pDNA, plasmid DNA; D-SPM, dextran-spermine.

\section{Discussion}

It is thought that $\mathrm{F}$ and $\mathrm{HN}$ glycoproteins interact with one another to promote $\mathrm{F}$ activity and, therefore, immunization with a DNA plasmid encoding both $\mathrm{F}$ and $\mathrm{HN}$ genes would be more effective than either component alone..$^{20-22}$ Therefore, in this research, the DNA plasmid pIRES-HN/F coexpressing $\mathrm{F}$ and $\mathrm{HN}$ proteins was constructed and used for in ovo immunization against NDV. Immunization with $40 \mu \mathrm{g}$ of pIRES-HN/F per egg induced a significant level of antibody titer; however, it was not effective in protecting against the virus challenge. This deficiency may be correlated to the relatively low transfection efficiency of the pDNA into the cells. Enzymes and serum proteins such as endonucleases may degrade the plasmid, and thereby reduce the available plasmids in the host cells that express the antigen.

In the present study, $1 \times 10^{5} \mathrm{EID}_{50}$ of the virulent NDV was used by the nasal route for challenge trials.

This dose was considered to be high to test the efficacy of the DNA vaccines. Therefore, the trial infection can be applied on statistically significant number $(\geq 10)$ of adult and young chickens (contact challenge) with a viral standard dose as $10^{5} \mathrm{EID}_{50}{ }^{23}$ Thus, virus challenges via contact route rather than nasal route may provide more protection against virulent viruses.

For most DNA vaccines, direct inoculation has been shown not to be effective enough due to electrostatic repulsion between the negatively charged DNA and positively charged cell membrane. Enzymatic degradation is another negative point that subsequently inhibits effective cellular uptake. DNA hydrolyzing activity by DNase I is also observed in blood plasma. Hence, the amount of foreign DNA that crosses the cytoplasm varies and depends on the DNase I activity. ${ }^{24}$

Therefore, to deliver DNA molecules into cells, a studies have used D-SPM, which is a polycationic polysaccharide. ${ }^{25,26}$ D-SPM can bind to DNA through a combination of electrostatic attraction and intercalation. In this study, D-SPM was used as a nanoparticle for in ovo delivery of a DNA vaccine. The results showed that $\mathrm{pDNA} / \mathrm{D}-\mathrm{SPM}$ complex can induce antibody titer in a low level compared to pDNA alone. The results of in ovo immunization are summarized in Table 4; the table shows $(P>0.05)$ low $\mathrm{S} / \mathrm{P}$ ratio obtained by ELISA at 4 weeks post-immunization of groups injected with pDNA + D-SPM compared to groups injected with pDNA alone, suggesting that D-SPM may not be effective in delivering pDNA to the cell by an in ovo method, thus resulting in low pDNA transfection efficiency.

This deficiency in vaccine efficacy may be due to the number of positive charges and the charge spacing of polyamine molecules in pDNA/D-SPM complex within the amniotic liquid that surrounds the chicken embryo. Studies on $\lambda$-DNA concentration by spermine homologues showed that the midpoint concentration of polyamine homologues for contracting DNA and the hydrodynamic ranges of the condensates are dependent on the polyamine structure. ${ }^{26}$ On the other hand, the most abundant protein in white egg is ovalbumin, representing $54 \%$ of the total protein content. ${ }^{27}$ It has been shown that at $\mathrm{pH}$ levels between 9.6 and 6.6, there is transference

Table 3 Results of virus challenge with the NDV AF2240 strain after in ovo vaccination

\begin{tabular}{|c|c|c|c|c|c|c|c|}
\hline Vaccinated groups & Sample numbers & 2 days & 3 days & 4 days & 5 days & 6 days & Survived \\
\hline pIRES-HN/F (40 $\mu g$ pDNA) & 7 & 0 & 2 & 3 & 2 & 0 & 0 \\
\hline pIRES-HN/F (40 $\mu \mathrm{g}$ pDNA + D-SPM) & 7 & 0 & 2 & 3 & 1 & I & 0 \\
\hline pIRES-HN/F (20 $\mu g$ pDNA + D-SPM) & 6 & 0 & 2 & 3 & 1 & 0 & 0 \\
\hline PIRES & 10 & 0 & 3 & 5 & 2 & 0 & 0 \\
\hline
\end{tabular}

Note: Sample numbers are the numbers of hatched chicks after in ovo vaccination.

Abbreviations: NDV, Newcastle disease virus; pIRES, plasmid internal ribosome entry site; HN, hemagglutinin; F, fusion; pDNA, plasmid DNA; D-SPM, dextran-spermine. 
Table 4 Number of dead chickens at days post-challenge with IBS002 strain

\begin{tabular}{|c|c|c|c|c|c|c|c|c|}
\hline Vaccinated groups & Sample numbers & 2 days & 3 days & 4 days & 5 days & 6 days & 8 days & Survived \\
\hline pIRES-HN/F (40 $\mu g$ pDNA) & 7 & 0 & 0 & 2 & 2 & I & 0 & 2 \\
\hline pIRES-HN/F (40 $\mu \mathrm{g}$ pDNA + D-SPM) & 7 & 0 & 0 & 2 & 3 & I & 1 & 0 \\
\hline pIRES-HN/F (20 $\mu \mathrm{g}$ pDNA + D-SPM) & 6 & 0 & 0 & 2 & I & I & 1 & 0 \\
\hline PIRES & 10 & 0 & 0 & 4 & 4 & 2 & - & 0 \\
\hline
\end{tabular}

Note: Sample numbers are the numbers of hatched chicks after in ovo vaccination.

Abbreviations: pIRES, plasmid internal ribosome entry site; HN, hemagglutinin; F, fusion; pDNA, plasmid DNA; D-SPM, dextran-spermine.

of albumin to dextran when the two components are mixed, the amount of albumin lost being nearly equal to the gain in the new component, albumin plus dextran. ${ }^{28}$ Polysaccharide such as dextran shows high viscosity, which helps in the stabilization of emulsion with ovalbumin. ${ }^{29}$

Therefore, in the present study, low antibody titer induced in the chickens immunized with the pDNA nanoparticle can be related to the low efficacy of D-SPM in delivering pDNA to the embryo cell. According to the manufaturer's instrcutions, $\mathrm{S} / \mathrm{P}$ values lower than 0.5 are considered negative. Thus, in ovo vaccination resulted in a slight increase in antibody titers, which are too low to be considered as seroconversion.

The basis of immunity against NDV is circulating antibodies and cell-mediated immunity. In this study, the stimulation of B cells (antibodies) by the constructed plasmid was not strong enough to elicit $\mathrm{T}$ cell-independent induction of IgM antibodies. In summary, protection against lethal challenge could not be expected when DNA vaccines were delivered in ovo.

\section{Conclusion}

This study revealed that although in ovo vaccination did not confer significant protection from the subsequent NDV challenge, a significant increase in the production of antibodies in the chicks vaccinated with $\mathrm{pIRES}-\mathrm{HN} / \mathrm{F}$ was achieved. This is the first study to report on the testing of D-SPM for the delivery of pDNA in ovo. This study described a set of experiments investigating a new DNA vaccine containing NDV F and $\mathrm{HN}$ genes and D-SPM to support DNA delivery for in ovo vaccination to protect chickens against the lethal Newcastle disease. Further investigation using a different virus titer and contact route for challenge to test the efficacy of different immunizations will help improve the nanoparticle DNA vaccine. Biotechnological studies today have mainly focused on safe and efficient nanodelivery of pDNA into chicken embryo cells.

\section{Acknowledgments}

This work was funded by the Ministry of Science, Technology and Innovations (MOSTI), Malaysia, for the research grant (ERGS/1-2012/5527122), and Institute of Bioscience,
Higher Institution Centre of Excellence (IBS HICoE) grant from the Ministry of Higher Education, Government of Malaysia for the support of the doctoral research work for Ms Masoumeh. Authors would like to thank Malaysia International Scholarship, Ministry of Higher Education, Government of Malaysia for the support of Dr Mohamed E El Zowalaty through a postdoctoral scholarship award conducted at the Laboratory of Vaccine and Immunotherapeutics, Institute of Bioscience, Malaysia.

\section{Author contributions}

$\mathrm{AI}, \mathrm{SDH}, \mathrm{MHB}$, and ARO conceived and designed the study. MF, HM, PM, and MEZ carried out the experiments. MF, and HM performed the molecular genetic studies, immunoassays, sequence alignment, statistical analysis. MF, MEZ and PM performed the vaccination experiments. MF, HM, MEZ drafted the manuscript, all authors have contributed to writing and revising the manuscript. MEZ, MF, TJW, and AI revised the manuscript during all stages of submission. All authors read and approved the final paper.

\section{Disclosure}

The authors report no conflicts of interest in this work.

\section{References}

1. Takami A, Masanori B, Mitsuru A. Biodegradable nanoparticles as vaccine adjuvants and delivery systems: regulation of immune responses by nanoparticle-based vaccine. Adv Polym Sci. 2012;247:31-64.

2. Tang DC, Devit M, Johnston SA. Genetic immunization is a simple method for eliciting an immune response. Nature. 1992;356:152-154.

3. Johnston PA, Liu H, Connell T. Applications in ovo technology. Poultry Sci. 1997;76:165-178.

4. Moura L, Liu M, Vakharia VN. Development and evaluation of an in ovo plasmid DNA vaccine against infectious bursal disease virus. Int $J$ Poul Sci. 2007;16(11):784-791.

5. Oshop GL, Elankumaran S, Vakharia VN, Heckert RA. In ovo delivery of DNA to the avian embryo. Vaccine. 2003;21:1275-1281.

6. Perry MM, Sang HM. Transgenesis in chickens. Transgenic Res. 1993; $2: 125-133$.

7. Sharma JM. Embryo vaccination of specific-pathogen-free chickens with infectious bursal disease virus: tissue distribution of the vaccine virus and protection of hatched chickens against disease. Avian Dis. 1986;30: 776-780.

8. Sharma JM, Witter RL. Embryo vaccination against Marek's disease with serotypes 1,2 and 3 vaccines administered singly or in combination. Avian Dis. 1983;27(2):453-463. 
9. Hwang SJ, Davis ME. Cationic polymers for gene delivery: design for overcoming barriers to systemic administration. Curr Opin Mol Ther. 2001:3:183-191.

10. Pollard H, Remy JS, Loussouarn G, Demolombe S, Behr JP, Escande D. Polyethylenimine but not cationic lipids promotes transgene delivery to the nucleus in mammalian cells. J Biol Chem. 1998;273:7507-7511.

11. Berscht PC, Nies B, Liebendorfer A, Kreuter J. In-vitro evaluation of biocompatibility of different wound dressing materials. J Mater Sci Mater Med. 1995;4:201-205.

12. Larsen C, editor. Dextran Prodrugs. Christesen VA, Copenhagen, Denmark; 1990.

13. Hosseinkhani H, Azzam T, Tabata Y, Domb AJ. Dextran-spermine polycation: an efficient nonviral vector for in vitro and in vivo gene transfection. Gene Ther. 2004;11:194-203.

14. Eliyahu H. Novel dextran-spermine conjugates as transfecting agents: comparing water-soluble and micellar polymers. Gene Ther. 2005; 12:494-503.

15. Yudovin-Farber I, Eliyahu H, Domb AJ. Synthesis of cationic polysaccharides and use for in vitro transfection. In: Friedmann and Rossi, editors. Gene Transfer: Delivery and Expression of DNA and RNA. Cold Spring Harbor, NY: CSHL Press; 2007.

16. Abedini $\mathrm{F}$, Ismail $\mathrm{M}$, Hosseinkhani $\mathrm{H}$, et al. Effects of CXCR4 siRNA/ dextran-spermine nanoparticles on CXCR4 expression and serum LDH levels in a mouse model of colorectal cancer metastasis to the liver. J Cancer Manage Res. 2011;3:301-309.

17. Dipl C, Wolfgang L, Sympate G, Clausthal N. Particle size and stability analysis in turbid suspensions and emulsions with photon cross-correlation spectroscopy, pcss. New Ideas for Industry, Dresden, 6th International Nanotechnology Symposium; 2008. Available from: https://www sympatec.com/docs/PCCS/publications/PCCS_2008_SizeandStability. pdf

18. Couvreur P, Barratt G, Fattal E, Legrand P, Vauthier C. Nanocapsule technology. Crit Rev Ther Drug Carrier Syst. 2002;19:99-134.

19. Allan W, Gough R. A standard haemagglutination inhibition test for Newcastle disease (1): a comparison of macro and micro methods. Vet Rec. 1974;95(6):120-123.
20. Loke CF, Omar AR, Rahaa AR, Yusoff K. Improved protection from velogenic Newcastle disease virus challenge following multiple immunizations with plasmid DNA encoding for $\mathrm{F}$ and $\mathrm{HN}$ genes. Vet Immunol Immunopathol. 2005;106(3-4):259-267.

21. Sawanta PM, Vermab PC, Subudhic PK, et al. Immunomodulation of bivalent Newcastle disease DNA vaccine induced immune response by co-delivery of chicken IFN- $\gamma$ and IL-4 genes. Vet Immunol Immunopathol. 2011;144(1-2):36-44.

22. Stone-Hulslander J, Morrison TG. Detection of an interaction between the $\mathrm{HN}$ and $\mathrm{F}$ proteins in Newcastle disease virus-infected cells. $J$ Virol. 1997;71(9):6287-6295.

23. World Organization for Animal Health (OIE). Newcastle disease. In: Manual of diagnostic tests and vaccines for terrestrial animals, 2008;576-589. OIE, Paris, France.

24. Vasslov V, Laktionov PP, Rykova EY. Extracellular nucleic acids. Bio Essays. 2007;29:654-667.

25. Hud NV, Downing KH. Cryoelectron microscopy of $\lambda$-phage DNA condensates in vitreous ice: the fine structure of DNA toroids. Proc Natl Acad Sci U S A. 2001;98:14925-14930.

26. Vijayanathan V, Thomas T, Shirahata A, Thomas TJ. DNA condensation by polyamines: a laser light scattering study of structural effects. Biochemistry. 2001;40:13644-13651.

27. Li-chan ECY, Powrie WD, Nakai S. The chemistry of eggs and egg products. In: Stadelman WJ, Cotterill OJ, editors. Egg Science and Technology. Binghamton, NY: The Haworth Press Inc.; 1995:105-175.

28. Ponder E, Ruth V. The interaction of dextran with serum albumin, gamma globulin, and fibrinogen. J Gen Physiol. 1960;43:753-758.

29. Choi SJ, Kim HJ, Moon TW. Structural and emulsifying properties of ovalbumin-dextran conjugate. June 23-27, 2001. Institute of Food Technologists Annual Meeting, New Orleans, LA, USA.
International Journal of Nanomedicine

\section{Publish your work in this journal}

The International Journal of Nanomedicine is an international, peerreviewed journal focusing on the application of nanotechnology in diagnostics, therapeutics, and drug delivery systems throughout the biomedical field. This journal is indexed on PubMed Central,

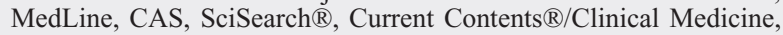

\section{Dovepress}

Journal Citation Reports/Science Edition, EMBase, Scopus and the Elsevier Bibliographic databases. The manuscript management system is completely online and includes a very quick and fair peer-review system, which is all easy to use. Visit http://www.dovepress.com/ testimonials.php to read real quotes from published authors. 